\title{
Comunicación
}

\section{DETERMINACIÓN DE ANTICUERPOS CONTRA Neospora caninum EN BÚFALOS DE AGUA (Bubalus bubalis) EN LA AMAZONÍA PERUANA}

\author{
Determination of Antibodies Against Neospora caninum in Water Buffaloes \\ (Bubalus bubalis) in the Peruvian Amazonia
}

\author{
Javier Jara V. ${ }^{1}$, Amanda Chávez V. ${ }^{1,2}$, Eva Casas A. ${ }^{1}$, Nofre Sánchez P. ${ }^{3}$, \\ Jorge Moreno-López ${ }^{4}$, Malik Merza ${ }^{4}$
}

\section{Resumen}

La neosporosis es una parasitosis de importancia en el sector ganadero por ser causante de abortos y mortalidad neonatal. El objetivo del estudio fue determinar la presencia de anticuerpos contra Neospora caninum en búfalos de agua procedentes de cinco centros de crianza ubicados en el distrito Jenaro Herrera, departamento de Loreto, Perú, en el año 2008. Se evaluaron 83 muestras de suero, obtenidas de búfalas en edad productiva, criadas para la producción de leche. Las muestras se evaluaron por ELISA indirecto e inmunofluorescencia indirecta (IFI). No se halló evidencia de anticuerpos contra $N$. caninum a las diluciones 1:25 y 1:100 utilizando ELISA indirecto, así como a la dilución 1:100 con IFI. Los resultados sugieren una baja o nula exposición de los búfalos de agua al parásito en la zona estudiada.

Palabras clave: Neospora caninum, búfalos de agua, anticuerpos, ELISA, IFI

\section{Abstract}

Neosporosis is an important parasitic disease that causes reproductive problems as abortion and neonatal mortality in diary cattle. The aim of the study was to determine the presence of antibodies againstNeospora caninum in water buffaloes reared in five farms located in Jenaro Herrera district, Loreto, Peru in 2008. Blood samples were collected from 83 female dairy buffalo older than 2 years. Serum samples were tested by indirect ELISA and immunnefluorescent antibody test (IFAT). None of sera presented antibodies against $N$. caninum to the dilution 1:25 and 1:100 using indirect ELISA or to the dilution 1:100 by IFAT. The results suggest a low exposition of water buffaloes to $N$. caninum in the studied area.

Key words: Neospora caninum, water buffaloes, antibodies, ELISA, IFI

${ }^{1}$ Laboratorio de Microbiología y Parasitología Veterinaria, Facultad de Medicina Veterinaria, Universidad Nacional Mayor de San Marcos, Lima

${ }^{2}$ E-mail: achavezvg@gmail.com

${ }^{3}$ Estación Experimental del Centro de Investigación IVITA-Iquitos, Iquitos

${ }^{4}$ Laboratorio SVANOVA, Suecia 
La neosporosis es causada por el protozoo Neospora caninum, reconocido como importante agente causal de aborto y mortalidad neonatal en bovinos (Dubey y Lindsay, 1996). Tiene un ciclo de vida heteroxeno, considerando como hospederos definitivos a los perros y coyotes, y como hospedero intermediario, principalmente al ganado bovino e incluso el mismo canino (McAllister et al., 1998; Gondim et al., 2004; Haji et al., 2007). La neosporosis ha sido reportada en varias especies domésticas (caprinos, ovinos, equinos, camélidos sudamericanos) incluyendo el búfalo de agua (Bubalus bubalis) (Dubey et al., 1998; Huong et al., 1998; Chávez et al., 2002).

El parásito presenta tres estadios de infección: taquizoito, bradizoito y ooquiste. Los dos primeros están presentes en tejidos de los hospederos infectados (intermediarios y definitivos), mientras que los ooquistes están presentes en las heces del hospedero definitivo (Bjorkman y Uggla, 1999). Tiene una vía de infección vertical de la madre gestante hacia el feto (transmisión transplacentaria) y una horizontal entre caninos y bovinos (transmisión posnatal) (Bergeron et al., 2000). Se conoce que la transmisión transplacentaria es la ruta más eficiente y de mayor frecuencia en el ganado bovino (Antony y Williamson, 2001; Dubey, 2003), sin embargo, no está definida la principal ruta de infección en el búfalo. Algunos estudios sugieren que la transmisión horizontal (ingestión de ooquistes) juega un papel importante en la persistencia de la infección en el hato, dado que el número de búfalos adultos seropositivos es mayor que en animales jóvenes (Guarino et al., 2000; Campero et al., 2007; Haji et al., 2007).

Anticuerpos contra N. caninum en búfalos ha sido reportada en diversos países, encontrándose una seropositividad que varía desde 0 a $71 \%$; sin embargo, la información acerca de neosporosis en los búfalos de agua en el Perú es nula. Se sabe que la neosporosis bovina es altamente prevalente en las principales cuencas lecheras, con niveles de anticuerpos de $57 \%$ en vacas de Arequipa (Andresen, 1999), 43\% en Cajamarca (Cabrera et al., 2000) y $30 \%$ en el valle de Lima (Silva et al., 2002). No obstante, en ganado cebú y sus cruces en la zona de Pucallpa, Perú, criados en forma extensiva se encontró solo el $1.5 \%$ de animales con anticuerpos contra N. caninum (Rivera et al., 2004).

El búfalo de agua representa la única fuente de ingresos para muchas comunidades rurales a nivel mundial. En el Perú, el búfalo de agua es poco utilizado y fue introducido a la llanura amazónica peruana por la Universidad Nacional de la Amazonía Peruana (UNAP) en 1966 (Isuiza et al., 1996); estimándose en la actualidad una población de 30,000 animales (Almaguer, 2007). El distrito de Jenaro Herrera, en el noreste de la selva peruana, Región Loreto, cuenta con 400 cabezas de ganado bufalino, y sus habitantes dependen económicamente de la producción lechera del búfalo (García, 2006).

El presente estudio se diseñó para determinar la presencia de anticuerpos contra $N$. caninum en búfalos de agua del distrito Jenaro Herrera. El trabajo se llevó a cabo en el año 2008 en cinco centros de crianza de ganado bufalino con propósito lechero. Cuatro eran centros de crianza privados y el quinto correspondió al hato de la Facultad de Agronomía de la UNAP. La zona del estudio queda en la margen derecha del río Ucayali, a $200 \mathrm{~km}$ al sur de la ciudad de Iquitos. La zona está considerada como bosque húmedo tropical, con precipitación pluvial anual de 2760 $\mathrm{mm}$, temperatura media de $26.8^{\circ} \mathrm{C}$, con máxima de $32.6^{\circ} \mathrm{C}$ y mínima de $21.1^{\circ} \mathrm{C}$, y humedad relativa anual de $87 \%$. El suelo es de tipo ultisol, de textura franco arenoso a franco arcilloso arenoso extremadamente ácido, y el nivel de materia orgánica es medio, con valores bajos de fósforo y potasio (Telecentros Rurales, 2010).

Se utilizó el método de tamaño muestral para una proporción de una población conocida (Thrusfield, 1990), considerando una prevalencia de $1.5 \%$, tomada de un estudio rea- 
lizado en Pucallpa (Rivera et al., 2004). Se consideró una población de 402 animales, nivel de confianza de $95 \%$ y un error esperado de 5\%, dando como resultado 22 animales; sin embargo, se trabajó con 85 búfalas mayores de dos años de edad. Se colectó muestras de sangre por punción yugular. Los sueros se trasladaron al Laboratorio de Parasitología de la Facultad de Medicina Veterinaria de la Universidad Nacional Mayor de San Marcos, Lima, para su procesamiento.

Se confirmó que el conjugado anti-IgG bovino reacciona con la IgG de los búfalos, lo cual se manifestó a través de una reacción positiva mostrada por un cambio de coloración. Luego, se empleó la técnica de ELISA indirecto, mediante un kit comercial de Neospora caninum Iscom ELISA, (SVANOVA BIOTECH AB) para la detección de anticuerpos contra $N$. caninum. Se utilizaron dos diluciones (1:25 y 1:100) en los sueros. Además, para confirmar el diagnóstico, las muestras que resultaron sospechosas se analizaron con la técnica de inmunofluorescencia indirecta.

No se encontró evidencia de anticuerpos contra $N$. caninum en los búfalos de agua evaluados con la técnica de ELISA indirecto en las dos diluciones. Todas las muestras presentaron valores menores al punto de corte $(<20)$. Con el fin de confirmar los resultados obtenidos con la técnica de ELISA, 11 sueros que presentaron los valores más altos de densidad óptica (OD) se analizaron mediante la técnica de inmunofluorescencia indirecta a dilución 1:100, sin que alguno de ellos evidenciara fluorescencia completa. Este hallazgo indicaría que los animales no estuvieron expuestos al parásito, ya sea por transmisión vertical o horizontal, o que los niveles de anticuerpos contra dicho agente fueron inferiores a la menor dilución (1:25) usada en este estudio.

Dentro de los posibles factores que estarían limitando la difusión de $N$. caninumen la zona sería el tipo de manejo realizado con los animales y el bajo número de caninos domésticos. Luego de la primera importación de búfalos procedentes del estado Río Grande del Sur-Brasil (Isuiza et al., 1996), se hicieron otras importaciones de búfalos de la misma zona; sin embargo, la seroprevalencia reportada en esa zona brasilera era relativamente baja (Flôres et al., 2006); de allí que existe la posibilidad que el número de animales infectados que hayan sido importados fue bastante baja o nula. Existe un reporte en China, donde ningún búfalo de agua (0/ 40) presentó evidencia de anticuerpos contra N. caninum (Yu et al., 2007).

Aunque la transmisión vertical ocurre en búfalos, y esta es una ruta de infección frecuente y eficiente en el ganado bovino (Dubey, 2003), no está clara la ruta de infección más común en el búfalo; aunque algunos autores indican que es la transmisión horizontal (Guarino et al., 2000; Campero et al., 2007; Haji et al., 2007). Sin embargo, para que exista la posibilidad de transmisión horizontal, se requiere la presencia de hospederos intermediarios positivos, ya sean bovinos, ovinos o caprinos, que sean a su vez presas de perros, pero estos hospederos intermediarios no están presentes en la zona de estudio. Asimismo, el número de perros en la zona es mínimo y no están en contacto directo con los búfalos de agua, frenando la posibilidad de infección por esta vía. Otro dato importante a tener en cuenta es el bajo porcentaje de mortalidad de neonatos (1-2\%, García, 2006), y dichas muertes, al decir de los criadores, son generalmente por accidentes, y no como producto de posibles infecciones que causen abortos.

Es importante recalcar que si bien, no se halló la presencia de anticuerpos contra Neospora caninum en los cinco centros de crianza ubicados en el noreste de la Amazonía peruana, esto no implica que todos los animales sean seronegativos. 


\section{Literatura Citada}

1. Almaguer Y. 2007. El búfalo, una opción de la ganadería. [Internet], [2 agosto 2008]. Disponible en: http://www.veterinaria .org/ revistas/redvet/n080807.html

2. Andresen H. 1999. Neosporosis en el Perú y el mundo. Rev Cienc Vet 15: 30-31.

3. Antony A, Williamson NB. 2001. Recent advances in understanding the epidemiology of Neospora caninum in cattle. N Z Vet J 49: 42-47.

4. Bergeron N, Fecteau G, Paré J, Martineau R, Villeneuve A. 2000. Vertical and horizontal transmisión of Neospora caninum in diary herds in Québec. Can Vet J 41: 464-467.

5. Bjorkman C, Uggla A. 1999. Serological diagnosis of Neospora caninum infection. Int J Parasitol 29: 1497-1507.

6. Cabrera M, Ortiz P, Claxton J, Williams D, Trees A. 2000. Evidencia serológica de infección por Neospora caninum en ganado vacuno en Perú. En: IV Congreso Peruano de Parasitología. Lima.

7. Campero CM, Pérez A, Moore DP, Crudeli G, Benitez D, Draghi MG, Cano D, Konrad JL, Odeón AC. 2007. Occurrence of antibodies against Neospora caninum in water buffaloes (Bubalus bubalis) on four ranches in Corrientes province, Argentina. Vet Parasitol 150: 155-158.

8. Chávez A, Serrano E, Casas E, Ortega L. 2002. Neospora caninum en camélidos sudamericanos peruanos. Rev Inv Vet, Perú 13(2): 92-93.

9. Dubey JP. 2003. Neosporosis in cattle. J Parasitol 89: 42-56.

10. Dubey JP, Lindsay DS. 1996. A review of Neospora caninum and neosporosis. Vet Parasitol 67: 1-59.

11. Dubey JP, Romand S, Hilali M, Kwok OCH, Thullies P. 1998. Seroprevalence of antibodies to Neospora caninum and Toxoplasma gondii in water buffaloes (Bubalus bubalis) from Egypt. Int $\mathbf{J}$ Parasitol 28: 527-529.
12. Flôres F, Arenhart S, Viçosa F. 2006. Anticorpos anti-Neospora caninum em bovinos, ovinos e bubalinos no Estado do Rio Grande do Sul. Ciência Rural 36: 1948-1951.

13. García E. 2006. Diagnóstico del recurso ganadero en productores de la localidad de Jenaro herrera, Distrito de Jenaro Herrera, Provincia de Requena, Departamento de Loreto, Río Ucayali, margen derecha. Tesis de Ingeniero Agrónomo. Iquitos. Univ Nacional de la Amazonía Peruana. $61 \mathrm{p}$.

14. Gondim LFP, McAllister MM, Pitt WC, Zemlicka DE. 2004. Coyotes (Canis latrans) are definitive hosts of Neospora caninum. Int J Parasitol 34: 159-161.

15. Guarino A, Fusco G, Savini G, Di Francesco G, Cringoli G. 2000. Neosporosis en water buffalo (Bubalus bubalis) in southern Italy. Vet Parasitol 91: 15-21.

16. Haji MR, Goraninejad S, Hamidinejat H, Ghorbanpour M, Paryab R. 2007. Occurrence of Neospora caninum antibodies in water buffaloes (Bubalus bubalis) from the south-western region of Iran. Bull Vet Inst Pulawy 51: 233-235.

17. Huong LTT, Ljungstrom BL, Uggla A, Bjorkman C. 1998. Prevalence of antibodies to Neospora caninum and Toxoplasma gondii in cattle and water buffaloes in southern Vietnam. Vet Parasitol 75: 53-57.

18. Isuiza M, Pezo R, López J. 1996. Estudio sobre el búfalo de agua en Jenaro Herrera. Documento Técnico $N^{\circ} 23$. Iquitos: Instituto de Investigación de la Amazonía Peruana. 69 p.

19. McAllister MM, Dubey JP, Lindsay DS, Jolley WR, Wills RA, Mcguire AM. 1998. Dogs are definitive hosts of Neospora caninum. Int J Parasitol 28: 1473-1478.

20. Rivera H, Benito A, Ramos O, Manchego A. 2004. Prevalencia de enfermedades de impacto reproductivo en bovinos de la Estación Experimental de Trópico del Centro de Investigaciones IVITA. Rev Inv Vet, Perú 15: 120-126. 
21. Silva P, Chávez A, Rivera H, Casas E. 2002. Seroprevalencia de Neospora caninum en bovinos lecheros del Valle de Lima. Rev Inv Vet, Perú 13(2): 51-55.

22. Telecentros Rurales. 2010. Distrito de Jenaro Herrera. [Internet], [20 noviembre 2010]. Disponible en: http:// www.telecentros.pe/jherrera/ geografica.shtml/
23. Thrusfield M. 1990. Epidemiología veterinaria. Zaragoza: Acribia. 352 p.

24. Yu J, Xia Z, Liu Q, Liu J, Ding J, Zhang W. 2007. Seroepidemiology of Neospora caninum and Toxoplasma gondii in cattle and water buffaloes (Bubalus bubalis) in the People's Republic of China. VetParasitol 143:79-85. 